\title{
Fitorreguladores e luminosidade na indução à calogênese em explantes foliares de Eugenia involucrata DC.
}

\author{
Phytoregulators and lightness in the induction of calli in leaves explants of \\ Eugenia involucrata DC.
}

\section{Diego Pascoal Golle ${ }^{\mathrm{I}}$, Lia Rejane Silveira Reiniger ${ }^{\mathrm{II}}$, Charlene Moro Stefanel ${ }^{\mathrm{III}}$, Caetano Miguel Lemos Serrote ${ }^{\mathrm{IV}}$, Silvia Machado dos Santos Rabaiolliv, Karol Buuron da Silva ${ }^{\mathrm{VI}}$}

\begin{abstract}
Resumo
Eugenia involucrata é uma espécie florestal nativa do Brasil com grande potencial para uso madeireiro, frutícola e medicinal. O presente estudo objetivou avaliar a influência de fitorreguladores e da luminosidade sobre a calogênese em discos foliares de Eugenia involucrata. Foi conduzido um experimento bifatorial ( $2 \times 5)$, cujos tratamentos consistiram na combinação da ausência ou presença de luz durante o cultivo e de cinco diferentes empregos de fitorreguladores: ANA, 2,4-D, BAP e as combinações ANA + BAP e 2,4-D + BAP, todos a $5 \mu \mathrm{M}$, em meio nutritivo MS. Após 45 dias de cultivo in vitro foi observado que a ausência de luz durante o período de cultivo reduz a oxidação fenólica favorecendo, assim, a calogênese, especialmente na presença de ANA e das combinações ANA + BAP e 2,4-D + BAP. O uso de 2,4-D e de BAP, isoladamente, não é favorável à calogênese em discos foliares de Eugenia involucrata.
\end{abstract}

Palavras-chave: Cultivo de calos; Cultura de tecidos; Myrtaceae

\begin{abstract}
Eugenia involucrata is a native forest species from Brazil with great potential for timber, fruit and medical purpouses. This study aimed to evaluate the influence of growth regulators and the effect of light on calli induction from leaves disks of Eugenia involucrata. A bifactorial experiment $(2 \times 5)$ was conducted, in which the treatments consisted in the combinations of absence or presence of light during cultivation and five different uses of phytoregulators: NAA, 2,4-D, BAP and combinations of NAA and BAP, 2,4-D and BAP, all at $5 \mu \mathrm{M}$, in the nutritious medium MS. After 45 days of in vitro cultivation, it was observed that the absence of light during the cultivation period reduced phenolic oxidation, thus stimulated calogenesis, mainly in the presence of ANA and the combinations NAA + BAP and 2,4-D + BAP. The use of 2,4-D and BAP, on isolated way, did not favor calli formation in leaves disks of Eugenia involucrata.
\end{abstract}

Keywords: Calli culture; Tissue culture; Myrtaceae

\footnotetext{
Biólogo, Dr., Professor Titular, Pró-Reitor de Pós-Graduação, Pesquisa e Extensão, Universidade de Cruz Alta, Campus Universitário Dr. Ulysses Guimarães, Rod. Municipal Jacob Della Méa, km 5.6, CEP 98005-972, Cruz Alta (RS), Brasil. dgolle@unicruz.edu.br (ORCID: 0000-0002-5264-8007) Engenheira Agrônoma, Dra., Professora do Departamento de Fitotecnia, Centro de Ciências Rurais, Universidade Federal de Santa Maria, Av. Roraima, 1000, CEP 97105-900, Santa Maria (RS), Brasil. liarsr@ufsm.br (ORCID: 0000-0002-3243-671X)

III Engenheira Florestal, Dra., Centro de Ciências Rurais, Universidade Federal de Santa Maria, Av. Roraima, 1000, CEP 97105-900, Santa Maria (RS), Brasil. chastefanel@gmail.com (ORCID: 0000-0002-3173-8150)

IV Engenheiro Florestal, Me, Doutorando do Programa de Pós-graduação em Engenharia Florestal, Centro de Ciências Rurais, Universidade Federal de Santa Maria, Av. Roraima, 1000, CEP 97105-900, Santa Maria (RS), Brasil. serrotec@yahoo.com.br (ORCID: 0000-0002-0275-2201)

Engenheira Florestal, Dra., Centro de Ciências Rurais, Universidade Federal de Santa Maria, Av. Roraima, 1000, CEP 97105-900, Santa Maria (RS), Brasil.silviaufsm@gmail.com (ORCID: 0000-0003-1331-8803)

vı Engenheira Florestal, Dra., Centro de Ciências Rurais, Universidade Federal de Santa Maria, Av. Roraima, 1000, CEP 97105-900, Santa Maria (RS), Brasil. karolbuuron@hotmail.com (ORCID: 0000-0003-2174-2663)
} 


\section{Introdução}

Eugenia involucrata DC., conhecida popularmente como Cerejeira-do-mato, é uma Myrtaceae de ocorrência natural em vários estados brasileiros, entre eles o Rio Grande do Sul (CARVALHO, 2008). Apresenta características de interesse, como madeira de excelente qualidade e durabilidade; além de recursos não madeiráveis, como os frutos, que são muito apreciados (LORENZI, 2016; BACKES; IRGANG, 2002) e as folhas, que apresentam propriedades medicinais, sendo utilizadas na forma de chás com ação anti-inflamatória, antialérgica e antioxidante (DAMETTO, 2014).

Um dos obstáculos enfrentados para a instalação de povoamentos de Eugenia involucrata, além da baixa densidade de ocorrência de árvores adultas, o que dificulta a obtenção de sementes em quantidade que permita a produção de mudas em larga escala (SILVA et al., 2005), é o baixo índice de sincronia na floração e na frutificação dos indivíduos, fato observado em um remanescente de Floresta Estacional Subtropical em três anos consecutivos (TONETTO et al., 2013). Adicionalmente, seus frutos apresentam poucas sementes, normalmente uma ou duas (SILVA et al., 2005), as quais são altamente recalcitrantes, iniciando a perda de seu potencial germinativo após duas semanas de armazenamento (LORENZI, 2016; CARVALHO, 2008). Suas sementes, assim como as de outras espécies do gênero Eugenia, são sensíveis à redução do teor de água a valores inferiores a 45\% (DELGADO; BARBEDO, 2007).

A pesquisa direcionada à avaliação e seleção de métodos de propagação vegetativa para essa espécie ainda são incipientes, destacando-se, entre os trabalhos publicados, um relacionado à enxertia (LATTUADA et al., 2010) e três que avaliaram aspectos da cultura de tecidos como a desinfestação superficial de explantes semilenhosos e herbáceos (GOLLE et al., 2013), o efeito de fitorreguladores na multiplicação in vitro (GOLLE et al., 2017), e o efeito de fitorreguladores e a posição de explantes foliares na indução à calogênese (GOLLE; REINIGER, 2013).

Técnicas de cultura de tecidos vegetais podem proporcionar a obtenção de plantas in vitro por organogênese direta ou indireta, sendo que a segunda rota passa, obrigatoriamente, pela fase de calo (GRATTAPAGLIA; MACHADO, 1998). Dentre essas técnicas, a calogênese resulta no cultivo de massas celulares, denominadas calos, podendo representar um sistema de síntese in vitro contínua de substâncias bioativas de maneira sustentável (ANDRADE, 2002). Tal técnica tem sido amplamente explorada na biossíntese de metabólitos de interesse medicinal por espécies nativas brasileiras (SIMÕES et al., 2012; SIMÕES-GURGEL et al., 2012). Os calos podem ser obtidos a partir de diversos órgãos, dentre os quais o uso de explantes foliares merece destaque pela utilização mais frequente, como em Blighia sapida (WEBSTER et al., 2006), Paulowia tomentosa (CORREDOIRA et al., 2008), Salyx humboldtiana (SANTOS et al., 2005); Litchi chinensis (MA et al., 2009), entre outros.

Considerando-se que a madeira de Eugenia involucrata é extremamente rígida, dificultando seu uso em alguns processos como para a obtenção de celulose (CARVALHO, 2008), a cultura de tecidos por organogênese indireta pode favorecer a ocorrência de variantes, gerando variabilidade genética por meio de variação somaclonal. Essas variações podem ser utilizadas em eventuais programas de melhoramento, permitindo a geração de novas cultivares (AMIRATO, 1986), especialmente em espécies autógamas, dotadas de relativamente menor reserva de variabilidade genética, como é classificada essa espécie (CARVALHO, 2008).

Diante do exposto, o presente trabalho objetivou analisar a influência de diferentes formas de uso de fitorreguladores (isolados ou combinados) no meio nutritivo e da presença ou ausência de luz na obtenção de calos em discos foliares de Eugenia involucrata. 


\section{Material e métodos}

As matrizes doadoras dos explantes utilizados no experimento possuíam aproximadamente 2 anos de idade e encontravam-se em desenvolvimento em casa de vegetação, acondicionadas em vasos plásticos com dimensões de $24 \mathrm{~cm}$ de diâmetro por $22 \mathrm{~cm}$ de altura (aproximadamente $8 \mathrm{~L}$ de capacidade) contendo substrato Plantmax ${ }^{\circ}$. Bimestralmente, as plantas receberam um aporte nutricional com a inclusão de $400 \mathrm{~mL}$ de solução de nitrogênio, fósforo e potássio (N-P-K: 5-2020) a $1 \mathrm{gL}^{-1} \mathrm{e}$, quinzenalmente, a adição de $500 \mathrm{~mL}$ de solução de nitrogênio (ureia) a $1 \mathrm{gL}^{-1}$. Para a manutenção da sanidade das plantas e como pré-tratamento na desinfestação do material vegetal, pulverizaram-se, a cada 15 dias, a parte aérea e a superfície do substrato com solução à base de Cercobin700 $\mathrm{PM}^{\circledast}$ (Thiophanato metílico) a $1 \mathrm{gL}^{-1}$ e $100 \mathrm{mgL}^{-1}$ de Sulfato de estreptomicina, até o encharcamento total das plantas e da superfície do substrato. No dia anterior ao isolamento dos explantes, foi realizada uma pulverização adicional com a mesma solução.

$\mathrm{O}$ experimento foi conduzido utilizando-se o delineamento inteiramente casualizado em arranjo bifatorial $2 \times 5$, totalizando 10 tratamentos, os quais tiveram 10 repetições, totalizando 100 unidades experimentais. Os níveis do fator " $A$ " testados foram a presença ou a ausência de luminosidade no decorrer do experimento. A presença de luz foi obtida mantendo-se as unidades experimentais sob fotoperíodo de $16 \mathrm{~h}$, com intensidade luminosa de $20 \mu \mathrm{mol} \mathrm{m}^{-2} \mathrm{~s}^{-1}$ produzida por lâmpadas fluorescentes brancas frias do tipo luz do dia; enquanto a ausência de luminosidade se deu pela permanência dos frascos dentro de caixas de papelão cobertas por sacos plásticos escuros, mantidas na sala de cultivo sob as mesmas condições de ambiente, exceto a luminosidade. Já os níveis do fator " $\mathrm{B}$ " foram cinco diferentes maneiras de incluir fitorreguladores, todos a $5 \mu \mathrm{M}$, no meio nutritivo, a saber: ácido naftaleno acético (ANA), ácido 2,4-diclorofenoxiacético (2,4-D), 6-benzilaminopurina (BAP), todos isolados, além das combinações ANA + BAP e 2,4-D + BAP. A auxina 2,4-D não foi adicionada ao meio nutritivo combinada com ANA devido aos resultados observados em experimentos anteriores não terem sido favoráveis (dados não apresentados). Da mesma maneira, não foram incluídos controles negativos (ausência de fitorreguladores) haja vista a constatação, em ensaio prévio, de que não há calogênese em Eugenia involucrata na ausência de fitorreguladores (GOLLE, 2010). Cada unidade experimental foi composta por um frasco de vidro com capacidade para $150 \mathrm{~mL}$ contendo $30 \mathrm{~mL}$ de meio nutritivo MS (MURASHIGE; SKOOG, 1962) e três discos foliares, obtendo-se um total de 300 explantes.

O meio nutritivo utilizado foi o MS acrescido de $30 \mathrm{gL}^{-1}$ de sacarose, $100 \mathrm{mgL}^{-1}$ de mioinositol e $7 \mathrm{gL}^{-1}$ de ágar. $\mathrm{O} \mathrm{pH}$ do meio nutritivo foi ajustado para 5,8 posteriormente à inclusão dos fitorreguladores e antes da adição do ágar e da autoclavagem, a qual ocorreu por 20 min a $121^{\circ} \mathrm{C}$ e $1,5 \mathrm{~atm}$ de pressão. Para a vedação dos frascos foi utilizado papel alumínio.

Em laboratório, as folhas foram lavadas com o auxílio de esponja e detergente comercial e, em seguida, permaneceram em água corrente por $5 \mathrm{~min}$. Posteriormente, passaram pelo seguinte procedimento de desinfestação superficial em câmara de fluxo laminar: imersão em etanol a $70 \%(\mathrm{v} / \mathrm{v})$ por 30 segundos; enxágue em água destilada e autoclavada; imersão em solução de hipoclorito de sódio $(\mathrm{NaClO})$ a 1,5\% (v/v) por $15 \mathrm{~min}$; e, por fim, um triplo enxágue em água destilada e autoclavada. Para a confecção dos discos foliares, utilizou-se um cortador cilíndrico metálico (cortador de couro) com circunferência de 1,5 cm de diâmetro.

As unidades experimentais foram mantidas em sala de cultivo com temperatura controlada de $25 \pm 3^{\circ} \mathrm{C}$ e, aos 45 dias de cultivo in vitro, foram avaliadas as variáveis: porcentagem de oxidação fenólica (explantes oxidados com alterações na coloração decorrente da presença de compostos fenólicos), porcentagem de formação de calos (presença de calos nos explantes, independentemente de seu tamanho e desenvolvimento), média das notas atribuídas ao desenvolvimento dos explantes, média do somatório de notas atribuídas aos explantes (calculada pelo razão entre o somatório das notas atribuídas aos discos foliares e o número de discos foliares por unidade experimental, que equivaleu a três). As notas atribuídas aos calos foram: 0 ) ausência de formação calogênica; 1) calo cicatricial; 2) calogênese em toda a área de exposição celular e 
3) calo de aspecto rígido e desenvolvido (Figura 1). Foram considerados como calos de aspecto rígido e desenvolvido, as formações que demonstraram desenvolvimento da massa celular para além das bordas do tecido cicatricial, com aspecto geral firme e algumas áreas friáveis nas bordas (interface entre o tecido excisado e o meio nutritivo). Essas calosidades evoluíram em termos de tamanho e apresentaram, com o passar do tempo, a formação de raízes e estruturas putativas à embriogênese somática (dados estes ainda não publicados).

Figura 1 - Intensidade de formação de calos em explantes foliares de Eugenia involucrata (Cerejeira-do-mato), aos 45 dias de cultivo in vitro em meio nutritivo MS, e respectivas notas, em que: 0: ausência de formação de calos; 1: início de formações calogênicas nas bordas dos discos foliares; 2 : formação calogênica em toda a bordadura do disco foliar; 3 : formação de calos rígidos e desenvolvidos. Barra $=1 \mathrm{~cm}$

Figure 1 - Calli formation intensity in leaf explants of Eugenia involucrata after 45 days of in vitro culture on MS nutritive medium, in which the notes represent: 0 - absence of calli formation; 1- early callogenic formations on the edges of the disk; 2 - callogenic formation across the border of the leaf disk; and 3 represents a grade of " 3 ", formation of hard calli and developed. Bar $=1 \mathrm{~cm}$

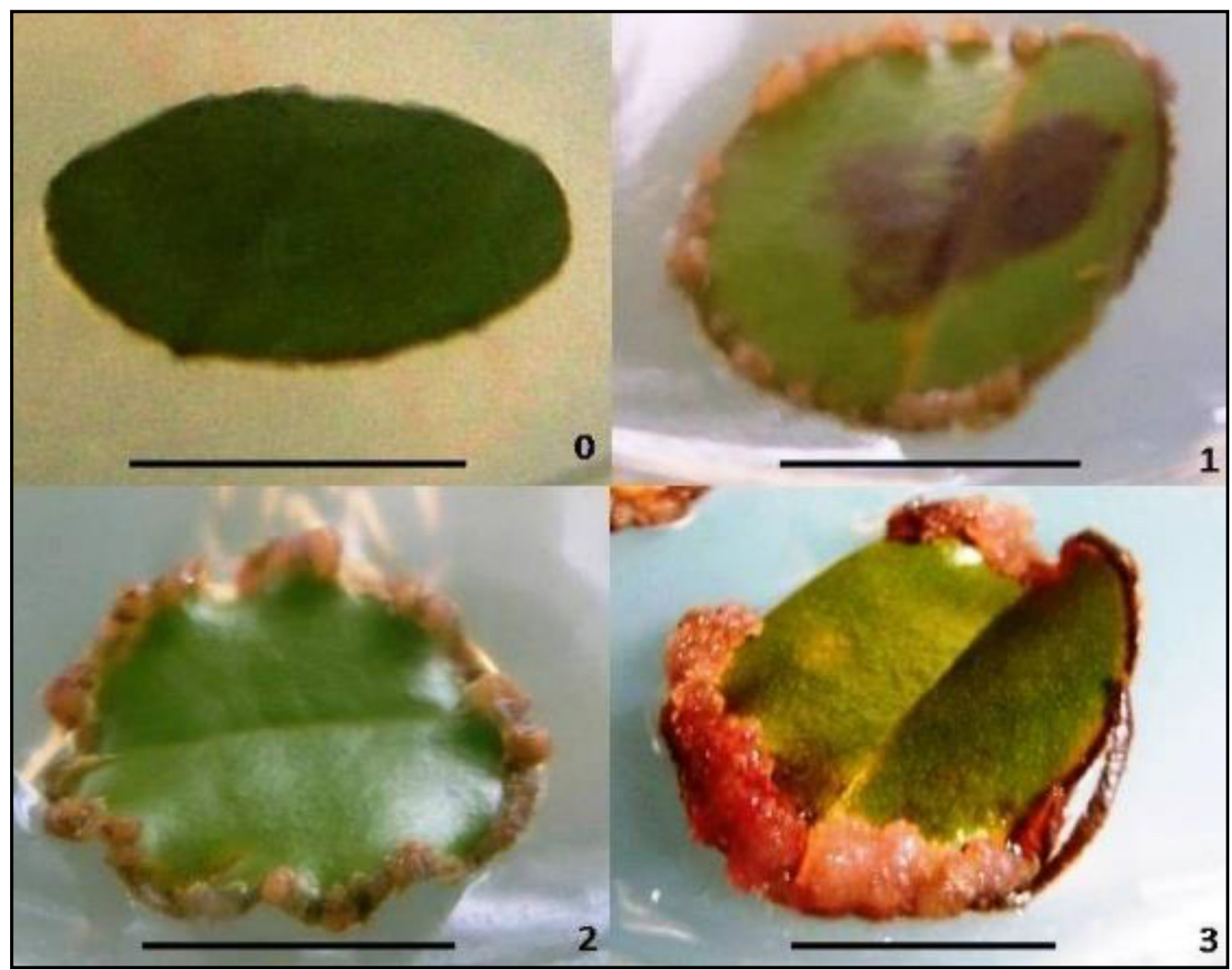

Fonte: Autores (2010)

Os dados foram transformados pela função $\sqrt{x+0,5}$ e submetidos à análise de variância. Utilizou-se a transformação após o teste de Kolmogorov-Smirnov de normalidade e a homogeneidade de variâncias por meio do teste de Bartlett. Quando o teste F foi significativo, as médias foram comparadas por meio do teste de Tukey a $5 \%$ de probabilidade de erro. Na exposição de dados, foram utilizados os valores reais observados. As análises foram efetuadas com o auxílio do programa estatístico SISVAR (FERREIRA, 2014). 


\section{Resultados e discussão}

Houve interação significativa entre os fatores testados para todas as variáveis avaliadas. No que se refere à oxidação fenólica $(\mathrm{p}=0,0015)$, as respostas mais promissoras foram observadas na ausência simultânea de luz e da auxina 2,4-D (Tabela 1). Na ausência de luz, o tratamento com 2,4-D (a $5 \mu \mathrm{M})$ promoveu a maior média de oxidação, Santos et al. (2005) relatam em seu trabalho possíveis efeitos fitotóxicos desta auxina. No entanto, de maneira geral, as oxidações não inviabilizaram o desenvolvimento dos calos, sobretudo quando ocorreram em manchas isoladas ou de forma branda. Na presença de luz, percebeu-se um aumento significativo nas oxidações (Tabela 1), sendo que a presença de compostos fenólicos inibiu o aumento da massa de calos e, em alguns casos, conduziu os tecidos à necrose impedindo o desenvolvimento dos calos e reiterando a observação de que, na ausência de luminosidade, a divisão celular é mais promissora.

A ausência de luminosidade foi favorável para a ocorrência de explantes sem sintomas de oxidação fenólica, provavelmente pela menor ação da enzima fenilalanina amoniliase (PAL) na ausência de luz. Essa enzima catalisa o processo de formação de compostos fenólicos pela eliminação de uma molécula de amônia da fenilalanina, formando o ácido cinâmico, sendo que sua atividade é ampliada por fatores como, por exemplo, a presença de luz (TAIZ; ZEIGER, 2013). Assim, na ausência de luminosidade, houve a redução de compostos fenólicos e, provavelmente, a canalização das rotas metabólicas das células para a formação de calos, propiciando os resultados de calogênese e de oxidação fenólica observados no presente estudo.

Em relação à formação de calos nos discos foliares $(\mathrm{p}=0,0155)$, de maneira semelhante ao observado para oxidação fenólica, a ausência de luminosidade foi mais favorável, especialmente quando foi utilizada a combinação 2,4-D + BAP, ambos a $5 \mu \mathrm{M}$, que, porém, não diferiu significativamente dos tratamentos que incluíram apenas ANA ou da combinação ANA + BAP (Tabela 1).

Tabela 1 - Médias de oxidação fenólica (\%), formação de calos (\%) e de desenvolvimento dos calos por atribuição de notas em discos foliares de Eugenia involucrata (Cerejeira-domato), aos 45 dias de cultivo in vitro em meio nutritivo MS, em função da interação entre a presença/ausência de luz e diferentes formas de uso de fitorreguladores a $5 \mu \mathrm{M}$

Table 1 - Average of phenolic oxidation (\%), calli formation (\%), calli development with based on the grades awarded in leave disks from Eugenia involucrata after 45 days of in vitro culture on

MS nutritive medium according to the interaction between absence or presence of light and different ways of use of phytoregulators $(5 \mu \mathrm{M})$

\begin{tabular}{lccc}
\hline & \multicolumn{3}{c}{----------Oxidação Fenólica (\%)-------------- } \\
\cline { 2 - 4 } Fitorreguladores a 5 $\boldsymbol{\mu M}$ & Presença de Luz & Ausência de Luz & Média \\
\hline ANA & 49,97 a b A & 23,33 aA & 36,65 \\
2,4-D & 29,98 a b A & 69,98 b B & 49,98 \\
BAP & 19,98 aA & 19,99 aA & 19,98 \\
ANA + BAP & 49,98 a b B & 9,99 a A & 29,98 \\
2,4-D + BAP & $73,31 \quad$ b B & 29,98 a b A & 51,64 \\
Média & 44,64 & 30,65 & \\
CV (\%) & & 20,24
\end{tabular}


Tabela 1 - Conclusão ...

Table 1 - Conclusion ...

\begin{tabular}{|c|c|c|c|}
\hline \multirow[b]{2}{*}{ Fitorreguladoresa $5 \mu \mathrm{M}$} & \multicolumn{3}{|c|}{ 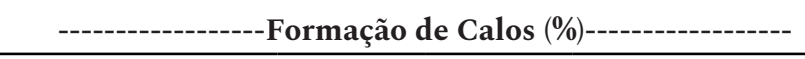 } \\
\hline & Presença de Luz & Ausência de Luz & Média \\
\hline ANA & $0,00 a^{*} B^{*}$ & 23,31 a b c A & 11,65 \\
\hline 2,4-D & $3,33 \mathrm{aA}$ & $3,33 \quad$ c A & 3,33 \\
\hline BAP & $9,99 \mathrm{aA}$ & 6,66 b c A & 8,32 \\
\hline ANA + BAP & 6,66 a B & $26,64 \mathrm{a} \mathrm{b} \quad \mathrm{A}$ & 16,65 \\
\hline 2,4-D + BAP & 3,33 a B & $33,30 \mathrm{aA}$ & 18,31 \\
\hline Média & 4,66 & 18,64 & \\
\hline \multirow[t]{2}{*}{$\mathrm{CV}(\%)$} & & 13,78 & \\
\hline & \multicolumn{3}{|c|}{ - } \\
\hline Fitorreguladores a $5 \mu \mathrm{M}$ & Presença de Luz & Ausência de Luz & Média \\
\hline ANA & 0,00 a B & 0,37 a b A & 0,18 \\
\hline 2,4-D & $0,03 \mathrm{aA}$ & 0,03 b A & 0,03 \\
\hline BAP & $0,10 \mathrm{aA}$ & $0,10 \quad \mathrm{~b} \mathrm{~A}$ & 0,09 \\
\hline ANA + BAP & 0,13 aA & $0,40 \mathrm{a} \mathrm{b} \mathrm{A}$ & 0,26 \\
\hline 2,4-D + BAP & 0,06 a B & $0,80 \mathrm{aA}$ & 0,43 \\
\hline Média & 0,06 & 0,33 & \\
\hline \multirow[t]{2}{*}{$\mathrm{CV}(\%)$} & & 21,90 & \\
\hline & \multicolumn{3}{|c|}{ 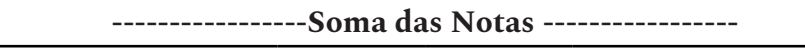 } \\
\hline Fitorreguladores a $5 \mu \mathrm{M}$ & Presença de Luz & Ausência de Luz & Média \\
\hline ANA & 0,00 a B & 1,10 a b A & 0,55 \\
\hline 2,4-D & $0,10 \mathrm{aA}$ & $0,10 \quad \mathrm{~b} \mathrm{~A}$ & 0,10 \\
\hline BAP & $0,30 \mathrm{aA}$ & $0,30 \quad \mathrm{~b} \mathrm{~A}$ & 0,30 \\
\hline ANA + BAP & 0,40 a B & $1,20 \mathrm{a} \mathrm{b} \mathrm{A}$ & 0,80 \\
\hline 2,4-D + BAP & 0,20 a B & $2,40 \mathrm{aA}$ & 1,30 \\
\hline Média & 0,20 & 1,02 & \\
\hline CV (\%) & \multicolumn{2}{|c|}{41,66} & \\
\hline
\end{tabular}

Fonte: Autores (2010)

Em que: * Médias seguidas pela mesma letra minúscula, na coluna, e maiúscula, na linha, não diferem entre si pelo teste de Tukey a 5\% de probabilidade de erro. A letra "a" é atribuída ao valor mais próximo do desejado para a variável em questão na cultura de tecidos.

A escala de notas atribuídas aos calos (Figura 1) foi eficiente na estratificação dos tratamentos, mais especificamente no que se refere à interação observada, em todas as variáveis avaliadas, entre os níveis dos fatores principais testados. Em relação à média das notas atribuídas aos explantes ( $\mathrm{p}=0,0137)$, novamente, a ausência de luminosidade foi mais favorável ao desenvolvimento das estruturas calogênicas em comparação à presença de luz, destacandose, da mesma maneira que na formação de calos, o tratamento 2,4-D + BAP (Tabela 1). Deve-se 
ressaltar, entretanto, que sempre em que houve a suplementação de ANA (isolado ou não), na ausência de luz, as médias foram superiores e não diferiram daquelas observadas no tratamento com 2,4-D + BAP.

Confirmando os resultados anteriormente apresentados, a variável obtida a partir da média da soma das notas atribuídas aos explantes $(\mathrm{p}=0,0142)$, evidenciou a interação entre os níveis dos fatores testados e o sinergismo existente entre o cultivo dos explantes na ausência de luz e os níveis do fator "B": ANA, ANA + BAP e 2,4-D + BAP (todos a $5 \mu \mathrm{M}$ ) (Tabela 1). No desdobramento das interações notou-se que a ausência de luz favoreceu a formação de calos, principalmente na presença de ANA, ANA + BAP e 2,4-D + BAP.

Assim, a ausência de luz foi extremamente favorável à formação de calos em discos foliares de Eugenia involucrata. Entretanto, na literatura, há resultados semelhantes e divergentes no que diz respeito ao efeito da luz na calogênese in vitro. Em Byrsonima intermedia, melhores médias foram obtidas quando os explantes foram cultivados no escuro, sendo que, para atingir o mesmo resultado na presença de luz, foram necessárias concentrações bem mais elevadas de fitorreguladores (NOGUEIRA et al., 2007). Também em Litchi chinensis houve vantagem no cultivo na ausência de luz na indução à calogênese em explantes foliares, sendo observada, neste caso, em particular, a formação de embriões somáticos a partir dos calos (RAHARJO; LITZ, 2007). Em Prunus serotina, a formação de calos para subsequente regeneração de plantas a partir de explantes foliares também ocorreu na ausência de luz. No entanto, em outro estudo com Litchi chinensis, Ma et al. (2009) relataram resultados opostos, sendo registrada maior formação de calos em explantes foliares na presença de luz. Contudo, em explantes foliares de Caesalpinia ferrea, tanto a ausência quanto a presença de luz associada ao uso de fitorreguladores proporcionou baixa formação de calos (SILVA et al., 2018).

De maneira geral, embora não diferindo, muitas vezes, do uso isolado de ANA, percebeuse, nitidamente, o sinergismo existente nas combinações entre as auxinas testadas e a citocinina, especialmente quando os discos foliares foram cultivados no escuro, não sendo favorável, como já relatado, o uso isolado do 2,4-D. Esses resultados diferem daqueles relatados por Lima et al. (2008), em Croton urucurana, em que 2,4-D, isoladamente, favoreceu de maneira significativa a indução de calos e, em contrapartida, sua associação com BAP não foi favorável. Em Kalanchoe pinnata foi obtida a indução de calos em $100 \%$ dos explantes com a combinação de $9,06 \mu \mathrm{M}$ de 2,4D e $8,88 \mu \mathrm{M}$ de BAP (SANTOS et al., 2014). Já para Ilex paraguariensis, os explantes cultivados na presença de $4,52 \mu \mathrm{M}$ de 2,4 -D apresentaram $60 \%$ de formação de calos, sendo observado que, em concentrações menores que 4,52 $\mu \mathrm{M}$ de 2,4-D e em concentrações maiores, a formação de calos foi inibida (STACHEVSKI; DEGENHART-GOLDBACH, 2011).

O desenvolvimento de calos evidencia a possibilidade de aprofundar pesquisas no sentido de otimizar os processos de desdiferenciação e rediferenciação celular in vitro, sendo fundamental, para isso, considerar que diferentes respostas poderão ser obtidas a partir de diferentes meios nutritivos, genótipos, além das características de competência e determinação celular que serão apresentadas pelas células. Cabe destacar que os calos que apresentaram maior massa em termos de desenvolvimento e aspecto majoritariamente firme, desenvolveram estruturas radiculares e também se mostraram putativos à embriogênese somática. Esses dados ainda não foram publicados. Esses resultados denotam a possibilidade de utilização dos calos para a regeneração de plantas, bem como o uso em programas de melhoramento, ensejando-se, entretanto, a continuidade das pesquisas.

\section{Conclusão}

A ausência de luz durante o período de cultivo favorece a calogênese e reduz a oxidação fenólica, especialmente na presença de ANA $(5 \mu \mathrm{M})$ e das combinações ANA + BAP e 2,4-D + BAP (todos a $5 \mu \mathrm{M})$. O uso de 2,4-D $(5 \mu \mathrm{M})$ e de BAP $(5 \mu \mathrm{M})$, isoladamente, não é favorável à calogênese in vitro em discos foliares de Eugenia involucrata. 


\section{Referências}

AMIRATO, P. V. Control and expression of morphogenesis in culture. In: BHOJWANI, S.S. (Ed.) Plant tissue culture and its agricultural applications. Cambridge: Universitypress, 1986. p.2345.

ANDRADE, S. R. M. Princípios da cultura de tecidos vegetais. 58.ed., Planaltina: Embrapa cerrados, 2002. 16p.

BACKES, A.; IRGANG, B. Árvores do Sul: guia de identificação e interesse ecológico. Porto Alegre: Pallotti, 2002. p.275.

CARVALHO, P. E. Espécies arbóreas brasileiras. 1 ed. Brasília: Embrapa Informação Tecnológicas; Colombo: Embrapa Florestas, 2008. v.3, 593p.

CORREDOIRA, E.; BALLESTER, A.; VIEITEZ, A.M. Thidiazuron - induced high frequency plant regeneration from leaf explants of Paulownia tomentosamature trees. Plant Cell, Tissue and Organ Culture, Dordrecht, v.95, n.2, p.197-208, 2008.

DAMETTO, A. C. Estudo químico e avaliação da atividade biológica de Eugenia brasiliensis e Eugenia involucrata (Myrtaceae). 2014. 169 f. Tese (Doutorado em Química) - Universidade Estadual Paulista Júlio de Mesquita Filho, Instituto de Química de Araraquara. Araraquara, 2014.

DELGADO, L. F.; BARBEDO, C. J. Tolerância à dessecação de sementes de espécies de Eugenia. Pesquisa Agropecuária Brasileira, Brasília, v.42, p.265-272, 2007.

FERREIRA, D. F. Sisvar: a Guide for its Bootstrap procedures in multiplecomparisons. Ciência e Agrotecnologia, Lavras, v. 38, n. 2, p. 109-112, 2014.

GOLLE, D. P. Estabelecimento, multiplicação, calogênese, organogênese in vitro e análise da diversidade genética em acessos de Eugenia involucrata DC. 2010, 159 f. Tese (Doutorado em Engenharia Florestal) - Universidade Federal de Santa Maria. Santa Maria, 2010.

GOLLE, D. P.; REINIGER, L. R. S. Fitorreguladores e posição de explantes foliares na indução à calogênese em cerejeira-do-mato. Ciência Rural, Santa Maria, v.43, n.10, p.1759-1762, 2013.

GOLLE, D. P.; REINIGER, L. R. S.; BELLÉ, R. A.; CURTI, A. R. Desinfestação superficial de explantes isolados de ramos semilenhosos e herbáceos de Eugenia involucrata DC. (Myrtaceae). Cerne, Lavras, v.19, n.1, p.77-82, 2013.

GOLLE, D. P.; REINIGER, L. R. S.; STEFANEL, C. M.; MUNIZ, M. F. B.; SILVA, K. B. Combination of NAA and TDZ for in vitro multiplication of Eugenia involucrata DC. Revista Árvore, Viçosa, v. 41, n. 5, e410509, 2017.

GRATTAPAGLIA, D.; MACHADO, M. A. Micropropagação. In: TORRES, A.C.; CALDAS, L.S.; BUSO, J. A. Cultura de tecidos e transformação genética deplantas. Brasília: Embrapa-SPI/ Embrapa-SNPH, 1998. v.1, p.183-260.

LATTUADA, D. S.; SOUZA, P. V. D.; GONZATTO, M. P. Enxertia herbácea em Myrtaceae nativas do Rio Grande do Sul. Revista Brasileira de Fruticultura, Jaboticabal, v.32, n.4, p.1285$1288,2010$.

LIMA, E. C.; PAIVA, R.; NOGUEIRA, R. C.; SOARES, F. P.; EMRICH, E. B.; SILVA, A. A. N. Callusinduction in leafsegmentsofCrotonurucuranaBaill. Ciência e Agrotecnologia, Lavras, v.32, n.1, p.17-22, 2008.

LORENZI, H. (Ed). Árvores brasileiras: manual de identificação e cultivo de plantas arbóreas nativas do Brasil. 7 ed. Nova Odessa: InstitutoPlantarum, 2016. 384 p.

MA, X. Y.; YI, G. J.; HUANG, X. L. Leaf callus induction and suspension culture establishment in lychee (Litchi chinensisSonn.) cv. Huaizhi. ActaPhysiologiaePlantarum, Kraków, v.31, n.2, 
p.401-405, 2009.

MURASHIGE, T.; SKOOG, F. A revised medium for rapid growth and bio assays with tobacco tissue cultures. PhysiologiaPlantarum, Copenhagen, v.15, p.473-497, 1962.

NOGUEIRA, R. C.; PAIVA, R.; OLIVEIRA, L. M.; SOARES, G. A.; SOARES, F. P.; CASTRO, A. H. F.; PAIVA, P. D. O. Indução de calos em explantes foliares de murici-pequeno (Byrsonima intermedia A. Juss.). Ciência e Agrotecnologia, Lavras, v.31, n.2, p.366-370, 2007.

RAHARJO, S. H. T.; LITZ, R. E. Somatic embryogenesis and plant regeneration of litchi (Litchi chinensisSonn.) from leaves of mature phase trees. Plant Cell, Tissue and Organ Culture, Dordrecht, v.89, n.2-3, p.113-119, 2007.

SANTOS, B. R.; PAIVA, R.; MARTINOTTO, C.; NOGUEIRA, R. C.; PAIVA, P. D. O. Indução de calos friáveis em explantes foliares de salix (SalyxhumboldtianaWilld). Ciência Rural, Santa Maria, v.35, n.3, p.510-514, 2005.

SANTOS, M. R. A.; FERREIRA, M. G. R.; GUIMARÃES, M. C. M.; LIMA, R.A.; OLIVEIRA, C. L. L. G. Callogenesis in leaves of Kalanchoe pinnata Lam. by 2,4-D and BA action. Revista Brasileira de Plantas Medicinais, Campinas, v.16, n.3, supl. I, p.760-764, 2014.

SILVA, C. V.; BILIA, D. A. C.; BARBEDO, C. J. Fracionamento e germinação de sementes de Eugenia. Revista Brasileira de Sementes, Pelotas, v.27, n.1, p.86-92, 2005.

SILVA, D.; IMAKAWA, A. M.; BRUNO, F. M. S.; SAMPAIO, P. T. B. Indução de calos friáveis em explantes foliares e segmentos nodais de pau-ferro (Caesalpinia ferrea). Revista de Ciências Agrárias, Lisboa, v.41, n.4, p.181-190, 2018.

SiMÕes, C.; AlbAREllo, N.; CASTRO, T. C.; MANSUR, E. Productionofanthocyaninsby plantcellandtissueculturestrategies. In: ORHAN, I.E. Biotechnological production of plant secondary metabolites. 1.ed. Sharjah: Bentham, 2012. p.67-86.

SIMÕES-GURGEL, C.; ROCHA, A. S.; CORDEIRO, L. S.; GAYER, C. R. M.; CASTRO, T. C.; COELHO, M. G. P.; ALBARELLO, N.; MANSUR, E.; ROSA, A. C. P. Antibacterial activity of field-grown plants, in vitro propagated plants, callus and cell suspension cultures of Cleome rosea Vahl. JournalofPharmacyResearch, v.5, n.1, p.3304-3308, 2012.

STACHEVSKI, T. W.; DEGENHART-GOLDBACH, J. Efeito do 2,4D na indução de calogênese in vitro de folhas de erva-mate. In: Evento de Iniciação Científica da Embrapa Florestas, X, 2011, Colombo, PR. Anais ...Colombo, PR: Embrapa Florestas, 2011, p.32.

TAIZ, L.; ZEIGER, E. (Ed.). Fisiologia vegetal.5 ed. Porto Alegre: Artemed, 2013. 820 p.

TONETTO, T. S.; PRADO, A. P.; ARAÚJO, M. M.; SCCOTI, M. S. V.; FRANCO, E. T. H. Dinâmica Populacional e Produção de Sementes de Eugenia involucrata na Floresta Estacional Subtropical. Floresta e Ambiente, Seropédica, v.20, n.1, p.62-69, 2013.

WEBSTER, S. A.; MITCHELL, S. A.; REID, W. A.; AHMAD, M. H. Somatic embryogenesis from leaf and zygotic embyo explants of Blighiasapida"cheese" ackee. In Vitro Cellular and Developmental Biology - Plant, Columbia, v.42, n.5, p.467-472, 2006. 